\title{
The Development of Modified Prism Green House (PGH) to Form Quality Pure Salt in Rural Nambakor Sumenep, Indonesia
}

\author{
Susilo Indrawati and Lila Yuwana* \\ Department of Physics, Institut Teknologi Sepuluh Nopember, Keputih, Sukolilo, Kota SBY, Jawa Timur - 60111, \\ Indonesia; susilo.indra.its@gmail.com, lila@physics.its.ac.id
}

\begin{abstract}
Objectives: Toconstruct modified PGH in order to purify the content of salt production located in Nambakor, Sumenep, Indonesia and to verify the salt quality by using X-Ray Diffractometer (XRD). Methods: The dimension of modified PGH is the area of $7 \times 7 \mathrm{~m}$ with a height of $2.5 \mathrm{~m}$. The final reservoir and base layer of modified PGH are formed of geomembrane, while the roof is made of $6 \% \mathrm{UV}$ micro plastic. In addition, refractive index test by using refractometer A/B is performed to evaluate densities of salt samples. Findings: Eventually, we successfully turn out pure salt that have been verified by using XRD. Furthermore, we could understand the comparison of harvest time using conventional and modified PGH process. Improvements: Salt farmers in Nambakor will be able to diversify advantages of salt into industry and pharmacy purposes not just for daily consumption. Therefore, the beneficial improvement will gain the competitiveness of domestic salt production.
\end{abstract}

Keywords: Conventional Process, Modified Prism Green House (PGH), Refractometer, Salt Quality, X-Ray Diffractometer (XRD)

\section{Introduction}

Basically, salt is a chemical substance of $\mathrm{NaCl}$ compounded with impurities, namely calcium sulfate $\left(\mathrm{CaSO}_{4}\right)$, magnesium sulfate $\left(\mathrm{MgSO}_{4}\right)$ and magnesium chloride $\left(\mathrm{MgCl}_{2}\right)$. The quality of salt is determined by quantify the percentage of $\mathrm{NaCl}$. Commonly, the percentage of $\mathrm{NaCl}$ for daily consumption is less than $94 \%$. Moreover, the quality of salt depends on the location of seawater resources and the infrastructures of the salt industry. This is because ponds of collected seawater are influenced by compounds of the soil, therefore the content of $\mathrm{NaCl}$ is $84,76 \%-88,96 \%$.

The implementation of ceramics and geomembrane technology is one of methods to increase the production and quality of salt. This technology is expected to accelerate the evaporation process of salt production and also the crystallization process. Furthermore, salt crystals being produced do not come into contact with the soil. As a result, we could obtain clean and quality

\footnotetext{
*Author for correspondence

salt crystals, i.e., the percentage of salt by using ceramics and geomembrane technology are $89.79 \%-$ $95.72 \%$ and $79.71-(91.32 \%, 95.75 \%$, and $98.4 \%)$ respectively $\stackrel{1-3}{ }$.

In last 2016, Indonesia experienced crop failures. There was significant decrease of traditional salt production of 96\% from the previous year (from 2.9 million tons to 188 thousand tons). This is because there was a heavy rainfall in almost regions of Indonesia ${ }^{4}$.

The unpredictable of high intensity of rainfall led to creating a new innovation, namely Prism Green House (PGH). The PGH is a modification of a greenhouse system for supporting an evaporation of seawater into salt crystals by utilising airstream and humidity of air. By applying PGH, salt farmer in Sedayu Lawas Lamongan could produce salt that has percentage of $\mathrm{NaCl} 87.6 \%-$ 95\% 5 . This quality averagely does not meet Indonesian National Standard (SNI 01-3556-2000) for salt. Based on the standard, the minimum content of $\mathrm{NaCl}$ in salt for consumption purpose is $94.7 \%$. 
Economically, have researched traditional salt production in rural Sampang, Indonesia. This research reported that the production of salt is divided into 3 categories, namely an owner of salt farm, employees, and a tenant ${ }^{\underline{6}}$. Furthermore, it requires developing the community of salt farmers to strengthen internal network and to stabilise market price of salt.

In order to improve salt production despite the weather, we have formulated the modified PGH in rural Sumenep, Indonesia. The modified PGH allows salt production runs continuously although in rainy season. Moreover, this research attaints to diversify the using of traditional salt production in Sumenep by enhancing the purity of salt. The specification of modified PGH is an area of $7 \times 7$ meters with a height of 2.5 meters. Transparent roofs and walls allow sunshine passes through inside the modified PGH. In addition, pure salt can be obtained by utilising geomembranes in last two part of reservoirs/ponds. As a result, the diversification of salt produced by the modified PGH can be applied into pharmacy, medical, and industry purposes.

\section{Study Area}

Mostly, Indonesian salt productions are formed in Madura Island. One of area in Madura, in which has a lot of traditional productions, is Nambakor that has an area of $12.54 \mathrm{~km}^{2}$.

Nambakor is located near to lowland and near to a coast, therefore Nambakor community mostly live as salt farmers.

A map of Nambakor is depicted in the Figure 1. Commonly, salt farmers in Nambakor perform salt production in daytime. This is because that the prepared seawater requires to be evaporated by sunshine. However, in the rains, the people perform alternative activities as fish farmers.

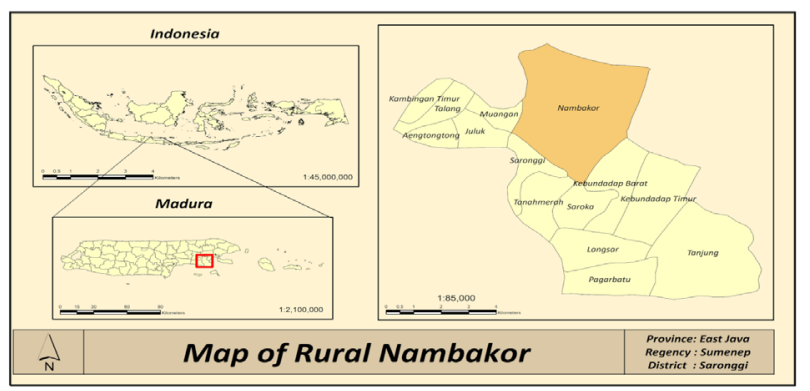

Figure 1. Map of rural nambakor, sumenep, east java Indonesia.

\section{Salt Quality}

The quality of salt is determined by a content of $\mathrm{NaCl}$ and impurities such as $\mathrm{Ca}, \mathrm{Mg}, \mathrm{SO}_{4}, \mathrm{Ba}$, and $\mathrm{Fe}$. The best quality means the percentage of $\mathrm{NaCl}$ is $100 \%$ and no impurities exist. Furthermore, the minimum requirements of percentage of $\mathrm{NaCl}$ for various purposes are governed by Ministry of Industry in the regulation No. $88 / \mathrm{M}-\mathrm{IND} / \mathrm{PER} / 10 / 2014$. The regulation is listed in Table 1, to be exact.

Table 1. The requirements of percentage of $\mathrm{NaCl}$ of salt for diverse purposes

\begin{tabular}{|l|c|c|c|c|}
\hline \multirow{2}{*}{ Parameter } & \multicolumn{2}{|c|}{ Consumption salt } & \multicolumn{2}{c|}{ Industrial Salt } \\
\cline { 2 - 5 } & $\begin{array}{c}\text { House- } \\
\text { hold }\end{array}$ & $\begin{array}{c}\text { Food } \\
\text { Industry }\end{array}$ & $\begin{array}{c}\text { CAP } \\
\text { Industry }\end{array}$ & Pharmacy \\
\hline $\mathrm{NaCl,} \mathrm{min} \mathrm{\%}$ & 94,0 & 97,0 & 96,0 & 99 \\
\hline $\mathrm{Ca}, \mathrm{Max} \%$ & 1,0 & 0,06 & 0,10 & 0,005 \\
\hline Mg, max \% & - & 0,06 & 0,05 & - \\
\hline Sulfat, max \% & 2,0 & - & 0,2 & 0,015 \\
\hline $\begin{array}{l}\text { Insoluble } \\
\text { material \% }\end{array}$ & 0,5 & 0,5 & - & - \\
\hline Water, max \% & 7,0 & 0,5 & 2,5 & 0,5 \\
\hline Fe(CN)6, ppm & 5,0 & - & - & - \\
\hline Iodium, ppm & $30-40$ & 10 & - & - \\
\hline Cd, ppm & 0,5 & 0,5 & - & - \\
\hline Pb, ppm & 10 & 10 & - & - \\
\hline Hg, ppm & 0,1 & 0,1 & - & - \\
\hline As, ppm & 0,1 & 0,1 & - & 3 \\
\hline Fe,ppm & 100 & - & - & 2 \\
\hline Al, ppm & - & - & - & 0,2 \\
\hline $\begin{array}{l}\text { Heavy metals, } \\
\text { ppm }\end{array}$ & - & - & - & 5 \\
\hline
\end{tabular}

\section{Competitiveness}

Recently, Indonesia is no longer being a large salt exporter, even has to import from Australia to satisfy the needs of salt. This is the consequences of the decrease of domestic salt production due to the frequent rainfall ${ }^{4}$. Moreover, the quality of domestic salt has deteriorated therefore the competitiveness of Indonesian salt is in low level. Based on the calculation using Revealed Comparative Advantage (RCA), the competitiveness of Indonesian is less than 1 (one). In other words, Indonesian salt is not competitive. Comparatively, the top three salt exporters, namely the Netherlands, Canada and Germany, have higher RCA 
higher than 4. Henceforth, researchers should contribute by applying a proper technology to pave the way for the problem of low quantity and low quality of domestic salt production.

\section{X-Ray Diffractometer (XRD)}

Determining the quality of salt requires evaluating the percentage of $\mathrm{NaCl}$ within salt, therefore we utilise XRD. An XRD is an accurate equipment to analyse substances within salt qualitatively and quantitatively. Specifically, we employed PANalytical Xpert-pro to examine various kinds of salt (Figure 2). Next, we analyse examinations results by using 'Highscore plus Analysis' software to determine constituents of salt and the percentage of $\mathrm{NaCl}$ in salt.

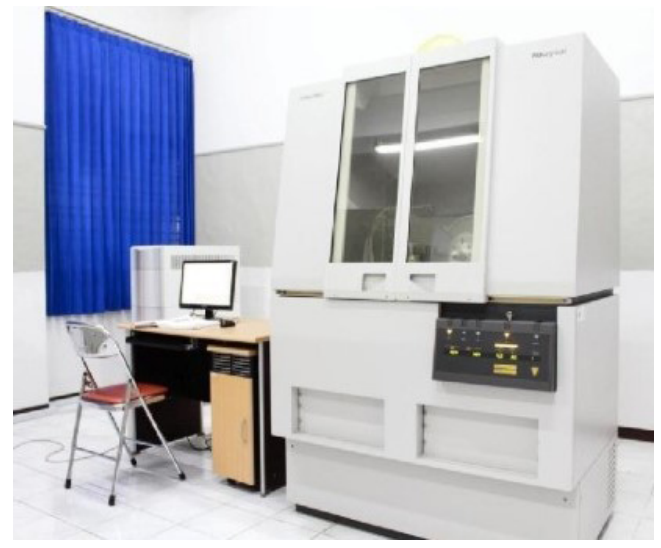

Figure 2. XRD PANalytical Xpert-pro.

\section{Methods}

\subsection{The Existing Condition}

The existing condition of salt production process in Namabakor is commonly applying High-Density PolyEthylene (HDPE) geomembrane, which we give the appellation 'conventional process', instead of using traditional process. This is because the using of conventional process could increase the content of $\mathrm{NaCl}$ to $95.75 \%$. We illustrate the conventional process in Figure 3, for step 1 to step 4. The last step is applied to filter and to be the last water aging process. Moreover, this step also behaves a crystal table in which salt is produced.

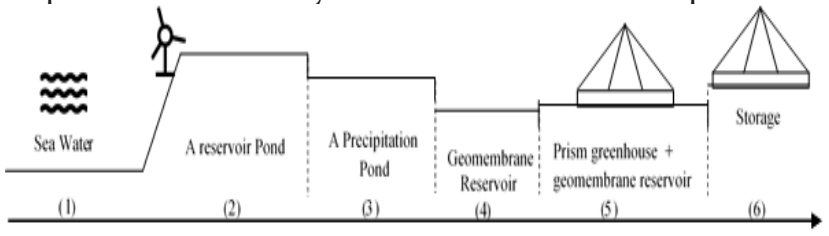

Figure 3. Salt production process.

\subsection{Design of Modified PGH}

This study offers modified PGH to purify salt produced in Nambakor (illustration in Figure 3, step 1 to step 6). The design of modified PGH is inspired by prism greenhouse constructed by, salt farmer from Lamongan, East Java. In 2018, Guntur researched Arifin's prism green house and evaluated the quality of salt. The research reported that the percentage of $\mathrm{NaCl}$ in salt produced by prism green house was 95\%. Henceforth, we propose the new design of prism green house, i.e. the modified PGH (prism green house) to form pure salt.

The design has an area of $7 \times 7 \mathrm{~m}$ with a height of 3 $\mathrm{m}$ (Figure 4) and consists of three main parts, i.e., $6 \% \mathrm{UV}$ plastic, plastic/tarpaulin Geomembrance and Bamboo. Similar as conventional salt production, modified PGH also has crystal table which aged seawater is poured on. The structure of modified PGH that makes a difference is a reservoir layered with geomembrane inserted before crystal table. Therefore, seawater is collected into reservoir in order to be prepared into aged seawater before poured into the crystal table.



Figure 4. Modified PGH in nambakor, sumenep.

Moreover, the structure of modified PGH (Figure 3) could be described as follows. Firstly, seawater: 1. is flowed into reservoir/pond, 2. to start evaporation process. Secondly, fresh seawater is precipitated in precipitation pond, 3, to separate seawater and other substances. Thirdly, seawater from precipitation pond is poured into geomembrane reservoir, 4 . to advance seawater aging process and to filter impurities. Next, seawater aging process is continuing on crystal table in the prism green house, 5. to crystallise aged seawater, and 6. pure salt obtained is collected and store it into storage. 


\subsection{Evaluation of Percentage of $\mathrm{NaCl}$ in Salt}

For evaluation purpose, salt has to be evaporated and shaped into dry powder. The steps of evaluation are shown in Figure 5.



Figure 5. Steps for examining $\mathrm{NaCl}$ levels in salt.

Salt samples produced by conventional and modified PGH process on crystal table are prepared into dry powder before quantified by XRD. After XRD examination, we analyse results by using 'Highscore Plus Analysis' software to determine the contents of salt and the percentage of $\mathrm{NaCl}$ in salt.

In addition, refractive index test by using refractometer $\mathrm{A} / \mathrm{B}$ is performed (Figure 6) to evaluated salt samples. Salt samples are collected for 7 days at 16.00 to be observed its refractive index differences.

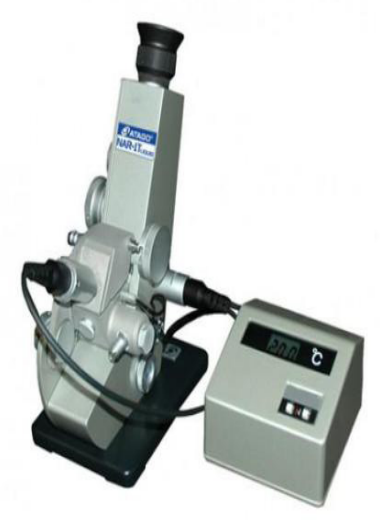

Figure 6. Refractometer A/B.

By evaluating refractive index differences every day, we are able to examine densities of salt samples. Therefore, we could understand the comparison of harvest time using conventional and modified PGH process.

\section{Results and Discussion}

\subsection{XRD Results of Conventional and Modified PGH Salt Samples}

We employ PANalytical Xpert-pro to examine the quality of salt samples. Next, we analysed examinations results by using 'Highscore Plus Analysis' software to determine constituents of salt and the percentage of $\mathrm{NaCl}$ in salt. Finally, characteristics of salt produced by conventional process (Figure 7) and modified PGH process (Figure 8) can be plotted as follows.

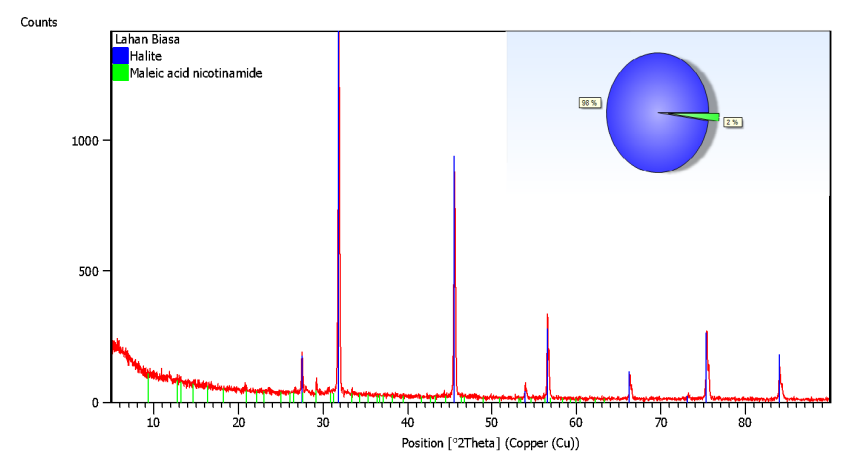

Figure 7. Percentage of the levels of compounds contained in salt using conventional process.

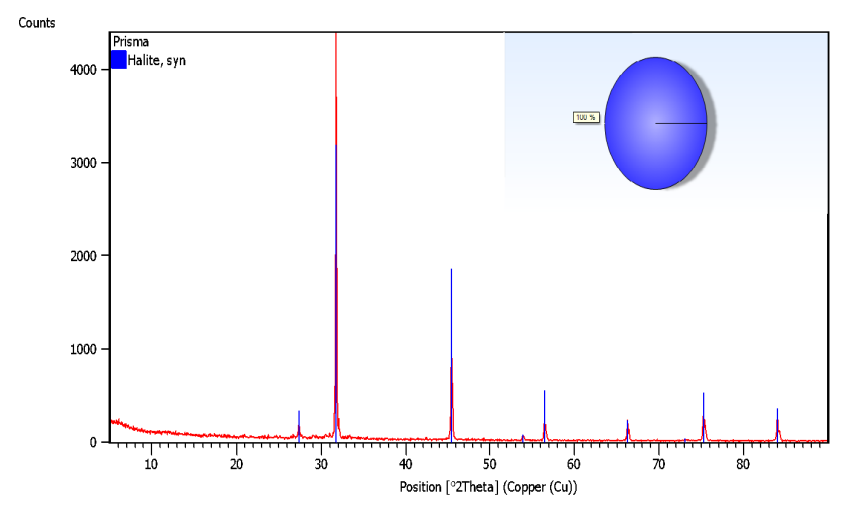

Figure 8. Percentage of the levels of compounds contained in salt using modified PGH.

Figure 7 shows salt produced by conventional process still have an impurity. As a result, the content of $\mathrm{NaCl}$ is less than $100 \%$, i.e. $98 \%$. The impurity embraced in salt is maleic acid nicotiamide, i.e. $2 \%$. On the contrary, Figure 8 reveals that salt sample formed by modified PGH is pure because the percentage of $\mathrm{NaCl}$ is $100 \%$. However, results of both conventional process and modified PGH does not 
reveal the existing of hazardous heavy metal, i.e. $\mathrm{Pb}, \mathrm{Hg}$, $\mathrm{Ag}$, and Cd. It means Nambakor seawater is suitable and safe to be resources of salt production.

\subsection{The Results of Refractive Index Test}

Refractive index test aims to determine the refractive index of aged seawater on the crystal table. The results obtained are depicted in Figure 9.



Figure 9. Refractive indexes of salt samples produced by conventional and modified PGH process.

Figure 9 shows refractive indexes of salt samples produced by conventional and modified PGH for 7 days. Generally, refractive indexes increase everyday due to an evaporation. The evaporation lead to the content of water in salt decrease significantly. However, the increase of refractive indexes of salt produced by conventional process is higher that modified PGH salt.

This is because there is no high airstream in the modified PGH to accelerate the evaporation process. In spite of these evaporation rates, the quality of modified PGH salt is more superior to conventional salt because the content of $\mathrm{NaCl}$ in modified $\mathrm{PGH}$ salt reaches $100 \%$. In other words, we could produce pure salt by applying modified PGH. The proof of this is explained in Section 7.1. Therefore, this research is able to diversify salt production in Sumenep by applying modified PGH. As a result, the diversification of salt can be implemented into pharmacy, medical, and industry purposes instead of only for consumption. Hopefully, this tremendous improvement will raise the competitiveness of domestic salt production.

\section{Conclusions}

We have evaluated salt samples produced by conventional and modified PGH process. The duration time of salt production required by both processes is quite the same. This is because sunshine is still able to evaporate in crystallisation process. However, the tremendous improvement on salt production is attained by using modified PGH. This is because modified PGH could produce pure salt that has been proved by XRD examination to result the percentage of $\mathrm{NaCl}$ is obviously $100 \%$. On the other hand, the conventional process yields $98 \%$. Henceforth, the diversification of salt can be applied into pharmacy, medical, and industry purposes instead of only for daily consumption. Furthermore, we firmly believe that the tremendous improvement will raise the competitiveness of domestic salt production. However, Nambakor seawater is suitable and safe to be resources of salt production. This is because we have proved scientifically that there is no harmful heavy metals within seawater in Nambakor.

\section{Acknowledgement}

The authors acknowledge to Arifin, the salt farmer in Sedayu Lawas, for the beneficial discussion about prism greenhouse. Moreover, we also acknowledge to The Ministry of Research, Technology, and Higher Education of The Republic of Indonesia for research funding of Pengabdian Masyarakat Berbasis Penelitian (Research Grant Program for Community Services Based on Research) 2018 according to Contact No. 1483/PKS/ ITS/2018.

\section{References}

1. Study of content of $\mathrm{Nacl}$ in raw and salt water produced and salt land productivity using different salt table media. Date accessed: 2015. https://translate.google.com/ translate?hl=en\&sl=id\&u=http://journal.trunojoyo.ac.id/ jurnalkelautan/article/view/804\&prev=search.

2. Quality monitoring of salt produced in Indonesia through seawater evaporation on HDPE geomembrane lined ponds. Date accessed: 2017. https://iopscience.iop.org/ article/10.1088/1742-6596/983/1/012166. 
3. Susanto H, Rokhatia N, Santosa WG. Development of traditional salt production process for improving product quantity and quality in Jepara District, Central Java, Indonesia, Procedia Environmental Sciences. 2015; 23:175-78. https://doi.org/10.1016/j.proenv.2015.01.027.

4. Kurniawan T, Azizi A. Climate change impact on salt ponds farmers in sampang and sumenep districts, Jurnal Masyarakat and Budaya. 2012; 14(3):499-518.
5. Development of salt production technology using prism greenhouse method. Date accessed: 2018. https://iopscience.iop.org/article/10.1088/1755-1315/106/ $1 / 012082$.

6. Helmi A, Sasaoka M. Dealing with socioeconomic and climate-related uncertainty in small scale salt producers in rural sampang, Indonesia, Journal of Rural Studies. 2018; 59:88-97. https://doi.org/10.1016/j.jrurstud.2018.02.005. 